\title{
Perceptions and Use of Herbal Remedies among Patients with Diabetes Mellitus in Murang'a North District, Kenya
}

\author{
Joshua Mwangi, Lucy Gitonga \\ Chuka University, Chuka, Kenya \\ Email: joshuakabugi@yahoo.co.uk, gitonga30@yahoo.com
}

Received 13 June 2014; revised 13 July 2014; accepted 13 August 2014

Copyright (C) 2014 by authors and Scientific Research Publishing Inc.

This work is licensed under the Creative Commons Attribution International License (CC BY). http://creativecommons.org/licenses/by/4.0/

(c) (7) Open Access

\section{Abstract}

Diabetes mellitus is a chronic disease with a world wide distribution. Use of herbal remedies has been on increase with World Health Organization estimating that 80 percent of the world's population presently uses some form of herbal medicine for some aspect of primary health care. Objectives of this study were therefore to determine the perceptions people with diabetes mellitus have towards herbal remedies, to determine the extent to which they use herbal remedies and also to establish whether there is any association between the perceptions people have on herbal remedies and use of herbal remedies. The study was carried out in Murang'a District, in Mathioya and Kangema Constituencies where five community health units were purposively selected to participate in the study based on their level of establishment in community health strategy. Data was collected using interview schedules. SPSS was used for data analysis. Significant findings from this study were: a significant number of the respondents $(15 \%)$ were diagnosed with diabetes mellitus when already admitted in the wards prior to which period they had no idea that they were diabetic, over $86 \%$ of those interviewed were given information on diabetes management on diagnosis and they attend hospital clinics for follow-up regularly and therefore this means that the reason for seeking alternative modes of treatment is not due to lack of information on diabetes but due to other reasons, $\mathbf{1 2 . 4 \%}$ of those interviewed admitted using herbal remedies as part of their management of diabetes. Recommendations made following the study were: the government of Kenya through Ministry of Health should encourage rigorous screening of clients and population in general for diabetes to ensure diabetes is diagnosed early and put under appropriate management and that the government of Kenya through Ministry of Health should put up a campaign educating diabetic patients on the potential dangers associated with combining herbal remedies with contemporary medicines due to their interactions. 


\section{Keywords}

\section{Diabetes Mellitus, Endocrinopathy, Gluconeogenesis, Herbal Remedy}

\section{Introduction}

\section{Background}

Diabetes mellitus is worldwide in distribution and the incidence of both type 1 and type 2 diabetes is increasing. The World Health Organization (WHO) estimated that about 177 million people in the world had diabetes in the year 2000 [1]. International Diabetes Federation's estimated that 194 million people had diabetes in the year 2003, and about two-thirds of these people lived in developing countries [2]. Diabetes incidence is increasing rapidly, and it is estimated that by 2030, the number of cases will almost double [3].

Diabetes mellitus occurs throughout the world, but is more common in developed countries. The greatest increase in prevalence is, however, expected to occur in Asia and Africa, where most patients will probably be found by 2030 [3]. The increase in incidence of diabetes in developing countries follows the trend of urbanization and lifestyle changes, perhaps most importantly a "Western-style" diet.

The most common type of diabetes is diabetes mellitus type 2 (NIDDM) which accounts for $85 \%$ of all diabetic cases in the developed countries and percentages are higher in developing countries. Diabetes mellitus type 1 (IDDM) accounts for the remaining 5\% - 15\% of all diabetic cases. The global pandemic is therefore principally type 2 diabetes and is associated with several contributing factors including obesity, unsatisfactory diet, sedentary lifestyle and increasing urbanization [4].

Recent studies reveal that diabetes is increasing faster in the world's developing economies than in developed countries. Seven out of ten countries with the highest number of people living with diabetes are in the developing countries. With an estimated 35 million people with diabetes, India has the world's largest diabetes population [5].

In kenya, diabetes mellitus prevalence has been on increase and is currently classified among the leading non-communicable diseases of public concern. Official statistics in Kenya note a diabetes prevalence of 3.5\%, but the government itself believes the rate is much higher, about $10 \%$ of the population [6]. Epidemiological surveys conducted by the Nairobi-based Diabetic Management and Information Center (DMI) gave the estimated prevalence of diabetes mellitus in Kenya at 3\% in 2003, and above 6\% in 2007. In some rural parts of the country such as Nyeri in central Kenya and Kilifi in the coast province the prevalence is as high as $11.6 \%$ and above $20 \%$ among the richer families in the major urban centers [7]

Diabetes mellitus can be managed in several ways including use of insulin, oral hypoglycaemic agents, diet and use of herbal remedies or combination of the above [8]. Currently diabetes has no cure but patients can be managed and live a relatively normal life free of complications. Diabetes can be managed using insulin, oral hypoglycaemics and diet combined with exercises. Of late however there has been documented evidence that many patients with chronic diseases like diabetes are opting to use alternative treatment like herbal remedies rather than using contemporary medicine [9].

\section{Literature Review}

\subsection{Introduction}

This chapter gives an overview of diabetes mellitus disease including the WHO definition, its clinical features, diagnosis and its management. It also gives the world prevalence of diabetes showing clearly why the disease has become a concern, with the world prevalence rate being $2.8 \%$ in the year 2000 and that rate expected to double by the year 2030 [10]. The chapter also looks at diabetes management including the use of herbal remedies.

\subsection{Definition of Diabetes}

Diabetes Mellitus is a condition in which a person has a high blood sugar (glucose) level, either because the body doesn't produce enough insulin, or because body cells don't properly respond to the insulin that is produced. 
Insulin is a hormone produced in the pancreas which enables body cells to absorb glucose, to turn it into energy [11].

WHO defines diabetes mellitus as a metabolic disorder of multiple etiology characterized by chronic hyperglycaemia with disturbances of carbohydrate, fat and protein metabolism resulting from defects in insulin secretion, insulin action, or both [10]. According to Mosby's Medical Dictionary, diabetes mellitus (DM) is a complex disorder of carbohydrate, fat, and protein metabolism that is primarily a result of a deficiency or complete lack of insulin secretion by the beta cells of the pancreas or resistance to insulin. All these definitions have one thing in common that diabetes mellitus is caused by either the body not producing insulin or the body cells not responding to the same. If the body cells do not absorb the glucose, the glucose accumulates in the blood (hyperglycemia), leading to vascular, nerve, and other complications [12]. Apart from affecting the metabolism of carbohydrates, proteins and fat, lack of insulin also causes significant disturbance of water and electrolyte homeostasis [8].

It is the commonest endocrine disorder that afflicts man and is a major cause of morbidity and mortality in the developed world while its prevalence in the developing countries is on increase [13].

\subsection{Types of Diabetes Mellitus}

There are many types of diabetes mellitus [12], the most common of which are:

\subsubsection{Type 1 Diabetes}

Also referred to as Insulin Dependent Diabetes Mellitus (IDDM). It is characterized by loss of the insulin-producing beta cells of the islets of Langerhans in the pancreas leading to insulin deficiency. This type of diabetes can be further classified as immune-mediated or idiopathic. The majority of type 1 diabetes is of the immunemediated nature, where beta cell loss is a cell mediated autoimmune attack [14]. There is no known preventive measure against type 1 diabetes, which causes approximately $10 \%$ of diabetes mellitus cases in North America and Europe. Most affected people are otherwise healthy and of a healthy weight when onset occurs. Sensitivity and responsiveness to insulin are usually normal, especially in the early stages. Type 1 diabetes can affect children or adults but was traditionally termed "juvenile diabetes" because it represents a majority of the diabetes cases in children.

\subsubsection{Type 2 Diabetes}

Also referred to as Non Insulin Dependent Diabetes Mellitus (NIDDM). It is characterized by insulin resistance which may be combined with relatively reduced insulin secretion. The defective responsiveness of body tissues to insulin is believed to involve the insulin receptor. However, the specific defects are not known. Diabetes mellitus due to a known defect are classified separately. Type 2 diabetes is the most common type and commonly affects subjects who are obese and insulin resistant, but these two factors alone are insufficient to cause diabetes unless they are accompanied by impaired beta cell function. This type of diabetes is also associated with genetics and environmental factors such as lifestyle, malnutrition in-utero age and pregnancy [15].

\subsubsection{Gestational Diabetes (GDM)}

This resembles type 2 diabetes in several respects, involving a combination of relatively inadequate insulin secretion and responsiveness. It occurs in about $2 \%-5 \%$ of all pregnancies and may improve or disappear after delivery. Gestational diabetes is fully treatable but requires careful medical supervision throughout the pregnancy. About $20 \%$ - 50\% of affected women develop type 2 diabetes later in life [16].

\subsubsection{Other Forms of Diabetes Mellitus Includes}

Diabetes due to genetic defects of beta-cell function under which are several forms of the diabetic state associated with monogenic defects in beta-cell function, frequently characterized by onset of mild hyperglycaemia at an early age (generally before age 25 years). They are usually inherited in an autosomal dominant pattern. Patients with these forms of diabetes, formerly referred to as maturity-onset diabetes of the young (MODY), have impaired insulin secretion with minimal or no defect in insulin action [17].

Diabetes due to genetic defects in insulin action which result from genetically determined abnormalities of 
insulin action. The metabolic abnormalities associated with mutations of the insulin receptor may range from hyperinsulinaemia and modest hyperglycaemia to symptomatic diabetes [18].

Diabetes due to Endocrinopathies. Several hormones (e.g. growth hormone, cortisol, glucagon, epinephrine) antagonize insulin action. Diseases associated with excess secretion of these hormones can cause diabetes (e.g. Acromegaly and Cushing's Syndrome) [3].

\subsection{Investigations}

Investigations carried out on diabetic patients include testing urine for glucose and ketones, measuring random or fasting blood sugar levels. Diagnosis is confirmed by demonstrating hyperglycemia i.e. fasting plasma glucose level at or above $7.0 \mathrm{mmol} / \mathrm{L}(126 \mathrm{mg} / \mathrm{dL})$. Plasma glucose at or above $11.1 \mathrm{mmol} / \mathrm{L}(200 \mathrm{mg} / \mathrm{dL})$ two hours after a $75 \mathrm{~g}$ oral glucose load as in a glucose tolerance test [10].

Glycosylated hemoglobin levels (HbA1c) may also be checked not for diagnosis but to provide an accurate and objective measure of glycaemic control over a period of weeks to months [19].

\subsection{Management of Diabetes Mellitus}

There is currently no cure for diabetes. The condition, however, can be managed so that patients can live a relatively normal life. Treatment of diabetes focuses on two goals: keeping blood glucose within normal range and preventing the development of long-term complications. Diabetes mellitus can be managed in several ways including use of insulin, oral hypoglycaemic agents, diet and use of herbal remedies or combination of the above [8].

\subsubsection{Dietary Management}

Diet and moderate exercise are the first treatments implemented in diabetes. For many Type II diabetics, weight loss may be an important goal in helping them to control their diabetes. A well-balanced, nutritious diet provides approximately $50 \%-60 \%$ of calories from carbohydrates, approximately $10 \%-20 \%$ of calories from protein, and less than $30 \%$ of calories from fat. The number of calories required by an individual depends on age, weight, and activity level. The calorie intake also needs to be distributed over the course of the entire day so surges of glucose entering the blood system are kept to a minimum (American Diabetes Association 2003). Diet management though usually described as the cornerstone of management (especially in type 2 diabetes) very few patients are able to follow dietary advice continuously [20].

\subsubsection{Oral Medications}

Oral medications are available to lower blood glucose in Type II diabetics. The drugs first prescribed for Type II diabetes are in a class of compounds called sulfonylureas and include tolbutamide, tolazamide, acetohexamide, and chlorpropamide. Newer drugs in the same class are now available and include glyburide, glimeperide, and glipizide. How these drugs work is not well understood, however, they seem to stimulate cells of the pancreas to produce more insulin. New medications that are available to treat diabetes include metformin, acarbose, and troglitizone. The choice of medication depends in part on the individual patient profile. All drugs have side effects that may make them inappropriate for particular patients. Some for example, may stimulate weight gain or cause stomach irritation, so they may not be the best treatment for someone who is already overweight or who has stomach ulcers. Others, like metformin, have been shown to have positive effects such as reduced cardiovascular mortality [21].

\subsubsection{Insulin}

Patients with Type I diabetes need daily injections of insulin to help their bodies use glucose. The amount and type of insulin required depends on the height, weight, age, food intake, and activity level of the individual diabetic patient. Some patients with Type II diabetes may need to use insulin injections if their diabetes cannot be controlled with diet, exercise, and oral medication. Injections are given subcutaneously, that is, just under the skin, using a small needle and syringe. Injection sites can be anywhere on the body where there is looser skin, including the upper arm, abdomen, or upper thigh. Purified human insulin is most commonly used, however, insulin from beef and pork sources also are available. Insulin may be given as an injection of a single dose of 
one type of insulin once a day. Different types of insulin can be mixed and given in one dose or split into two or more doses during a day [22].

\subsubsection{Alternative Treatment}

A variety of alternative therapies can be helpful in managing the symptoms of diabetes and supporting patients with the disease. Acupuncture can help relieve the pain associated with diabetic neuropathy by stimulation of certain points. A qualified practitioner should be consulted.

Herbal remedies also are helpful in managing diabetes. Herbal remedies have been in use since times immemorial. People on all continents have used hundreds to thousands of indigenous plants for treatment of ailments since prehistoric times [23]. Although there is no herbal substitute for insulin, some herbs may help adjust blood sugar levels or manage other diabetic symptoms [24]. Some options include:

- fenugreek (Trigonella foenum-graecum) has been shown in some studies to reduce blood insulin and glucose levels while also lowering cholesterol;

- bilberry (Vaccinium myrtillus) may lower blood glucose levels, as well as helping to maintain healthy blood vessels;

- garlic (Allium sativum) may lower blood sugar and cholesterol levels;

- onions (Allium cepa) may help lower blood glucose levels by freeing insulin to metabolize them;

- cayenne pepper (Capsicum frutescens) can help relieve pain in the peripheral nerves (a type of diabetic neuropathy);

- gingko (Gingko biloba) may maintain blood flow to the retina, helping to prevent diabetic retinopathy.

\subsection{Prevalence of Diabetes}

World Health Organization in the year 2000 estimated that, at least 171 million people worldwide suffered from diabetes, or $2.8 \%$ of the world population [3]. Its incidence is increasing rapidly, and it is estimated that by 2030, this number will almost double. Diabetes mellitus occurs throughout the world, but is more common (especially type 2) in the more developed countries. The greatest increase in prevalence is, however, expected to occur in Asia and Africa, where most patients will probably be found by 2030 [3].

In Africa, diabetes is now regarded as a major health threat, and according to IDF estimates, the number of people with diabetes in Africa will almost double in the 15 years leading up to 2010 [25]. There is a dearth of published studies describing the incidence and prevalence of type 1 diabetes in Sub-Saharan Africa. Type 1 diabetes is considerably rarer than type 2 disease, and large populations need to be surveyed. Also, to assess incidence, the population surveyed should be accurately known, and this is in itself difficult, as complete censuses in Africa are rare and migration in and out of study areas common. Elamin and colleagues in the Sudan in 1992 reported a survey of nearly 43,000 schoolchildren (age 7 to 11 years) and found a prevalence rate of 0.95 per 1000 [26]. This rate is comparable to a reported prevalence rate of 0.3 per 1000 in Nigeria [27]. The reported incidence is 10.1 per 100,000 children per year in Sudan [26] and 1.5 per 100,000 per year in Tanzania [28]. The discrepancy between the Sudanese and Tanzanian studies may be explained by ethnic differences, and perhaps problems related to the design of the studies.

Before the 1990s, type 2 diabetes was considered a rare medical condition in Africa. Epidemiological studies carried out in that decade, however, provided evidence of a trend toward increased incidence and prevalence of type 2 diabetes in African populations [29]. Africa is experiencing the most rapid demographic and epidemiological transition in world history [30].

\subsubsection{Ethnic Differences in Prevalence of Diabetes}

There are marked discrepancies between the prevalence of diabetes among different communities in Sub-Saharan Africa. Two studies in Sub-Saharan Africa have examined ethnic differences in the prevalence of diabetes. A difference was found between Indians, blacks, and Caucasians in South Africa, where Indians had the highest predisposition and were followed by blacks and Caucasians [31]. In the Tanzanian study, the indigenous African population had lower diabetes prevalence than the migrant Asian group (1.1 percent as opposed to 9.1 to 7.1 percent) [32] [33].

The prevalence of diabetes appears to be substantially higher in African-origin populations living abroad than in indigenous Africans. West Africans from Nigeria [34] and central Africans from Cameroon [35] were compared with populations of West African origin in the Caribbean [34] [35], United Kingdom [34] [35], and the 
United States [34]. These studies suggest that environment determines diabetes prevalence in these populations of similar genetic origin.

\subsubsection{Urban-Rural Differences}

Residence seems to be a major determinant of diabetes in Sub-Saharan Africa, since urban residents have 1.5 to 4.0 times higher prevalence of diabetes than their rural counterparts. This is attributable to lifestyle changes associated with urbanization and Westernization. The studies from Tanzania [36], showing an urban-to-rural ratio of five to one, and from Cameroon [35], with a ratio of two to one, both confirm the urban-rural discrepancy in diabetes prevalence and suggest the consequent likely increases because of urban migration.

Some of the factors that have been associated with this pandemic which consists primarily of type 2 diabetes include rapid cultural changes, aging populations, increasing urbanization, dietary changes, decreased physical activities and other unhealthy lifestyles and behavioral patterns [37].

Though the cases are spreading at an alarming rate, the situation is further complicated by the fact that less than half of the people with diabetes are diagnosed. For instance the prevalence of undiagnosed diabetes accounted for 60 percent of those with diabetes in Cameroon [35], 70 percent in Ghana [38], and over 80 percent in the recent study in Tanzania [36]. It would therefore appear that in Sub-Saharan Africa, for every diagnosed person with diabetes, there are one to three undiagnosed cases.

\subsection{Diabetes in Kenya}

In Kenya like the rest of the developing world the situation is not any different in respect to diabetes. Since 1960 there has been an increase in the number of known diabetics. Abdulla (1976) reported that as early as 1966 the magnitude of diabetes mellitus had become sizeable enough necessitating starting of diabetic clinic at Kenyatta National Hospital wholly devoted to diabetes. Kebaso (2003) stated that the same clinic (at KNH) was booking a minimum of 60 patients every week by the year 2000 [39]. Kenyatta National Hospital clinic is only one of the clinics dealing with diabetes. There are many such clinics spread all over Kenya including one based in Murang'a District Hospital where part of the study will be conducted. Latest findings quoted in East Africa Medical Journal (EAMJ) indicates that Kenya's prevalence of type 2 diabetes has now surpassed the World Health Organization (WHO) estimate of between $1 \%$ and $6 \%$, with incidence being as high as $14 \%$ in urban areas [40]. Diabetes is manageable and with good control of blood sugars diabetic patients can live long even without developing complications. Management of diabetes is through use of insulin, oral hypoglycaemics and through diet and change of lifestyle. Of late majority of patients with chronic diseases like diabetes have started shifting more towards use of herbal remedies. This has been as a result of increase in dissatisfaction with conventional medicine, increase in dissatisfaction with conventional medicine, increase in advertisement of herbal remedies and the perception that herbal remedies are natural and therefore causes less adverse effects in the body.

\subsection{Use of Herbal Remedies in Diabetes Management}

People on all continents have used hundreds to thousands of indigenous plants for treatment of ailments since prehistoric times. The use of, and search for, drugs and dietary supplements derived from plants have accelerated in recent years. Pharmacologists, microbiologists, botanists, and natural-products chemists are combing the Earth for phytochemicals and leads that could be developed for treatment of various diseases. In fact, according to the World Health Organisation, approximately 25\% of modern drugs used in the United States have been derived from plants [41].

There has been a gradual increase in use of alternative therapy worldwide. A survey released in May 2004 by the National Center for Complementary and Alternative Medicine focused on who used complementary and alternative medicines (CAM), what was used, and why it was used. The survey was limited to adults, aged 18 years and over in the year 2002, living in the United States. According to this survey, herbal therapy, or use of natural products other than vitamins and minerals, was the most commonly used CAM therapy (18.9\%) when all use of prayer was excluded (Barnes et al. 2004). In the United Kingdom, it is estimated that in 1996 alone, at least 72 million pounds was spent on alternative therapies (licensed herbal medicine, homeopathic remedies and essential oils for aromatherapy). Herbal remedies are very common in Europe. In Germany, herbal medications are dispensed by apothecaries (e.g., Apotheke). Prescription drugs are sold alongside essential oils, herbal extracts, or herbal teas. Herbal remedies are seen by some as a treatment to be preferred to pure medical compounds which have been industrially produced. In the UK, herbal remedies that are bought over the counter are 
regulated as supplements, same case with the US [42]. In USA approximately $40 \%$ of the annual expenditure on medicine can be attributed to sales of herbal remedies directly to the public and other naturopathic treatments [43].

Traditional herbs can be divided into three categories.

1) Licensed herbal products: These are the ones that are sold or supplied with claims for use as medicines.

2) Dried herbs which are exempted from licensing requirements. These are exempted under section 12 of the medicines Act and are sold or supplied with medicinal claims on labeling. These products, often sold as "teas" are prepared from dried, crushed or commuted (reduced to small fragments) plants and sold under their botanical names.

3) Herbal products sold as food supplements with no medicinal claims though some therapeutic value may be implied [43].

The World Health Organization (WHO) estimates that 80 percent of the world's population presently uses herbal medicine for some aspect of primary health care [41]. In the recent past there has been an increase in advertisements of herbal remedies as the best treatment of chronic diseases and existing data shows increase in use of herbal remedies the world over [43]. This use has not spared diabetics especially because of being promised cure following use of herbal remedies. Recent studies carried out in South Western United States among Hispanic diabetic women concluded that Use of herbal therapies is not uncommon among diabetic patients [44]. A recent study carried out in India on traditional herbal medicines used for the treatment of diabetes among two major tribal groups in south Tamil Nadu, India found there are traditional tribal healers who are respected herbalists. The same study found that there were two prominent in the study area who were reputed for preparing medicine for treating diabetes [45].

The situation has not been any different in Kenya which has in the recent past experienced an increase in demand of herbal medicine thereby leading to increase in number of herbal clinics and herbal products some of which are being sold in the supermarkets. Some of the reputable herbal clinics that has been in operation includes Makini herbal clinic, Tabibu herbal clinic, Kamirithu herbal clinic, Almed herbal clinic but many more has been opened.

Increase in demand and use of herbal remedies has lead to "quacks" infiltrating the herbal market. This is a big problem in that they lack the knowledge on herbal remedies and some of them are money driven and are therefore likely to mismanage patients leading to patients developing complications. In Murang'a there are both herbal clinics and organizations selling herbal remedies. The main herbal clinics are Kamirithu Herbal Clinic and Alpha Herbal and Nutritional Cures, while organizations selling herbal remedies include Dynapharm and Swissgarde. Some of the products being used include those from China India and America while others are prepared locally. Some of the areas mentioned by the herbalists as the areas they go for their herbs includes Arusha, Magadi, Narok and Namanga.

\section{Materials and Methods}

\subsection{Study Design}

Descriptive cross-section study design was used in this study in which diabetic patients in Murang'a district were purposively selected to participate in the study. Data was collected using structured interview schedule through which data on diabetes and its management among the respondents was collected.

\subsection{Study Area}

Murang'a North is one of the seven districts in the Central Province, Kenya. It is bordered by Nyeri District to the north, Maragua District to the southwest, Nyandarua District to the west and Kirinyaga District to the east (Figure 1).

Murang'a North District lies between latitudes 0 degrees 34'South and 1degree 7'South and longitudes 36 degrees East and 37 degrees 27'East. The district's total area is $930 \mathrm{Km}^{2}$ (Including the Aberdare Forest, which is $174 \mathrm{Km}^{2}$ ). It has administrative divisions namely Kiharu, Kahuro, Kangema and Mathioya. There are seventeen locations and seventy sub-locations. It has three local authorities namely; Murang’a Municipal Council, Murang’a County Council and Kangema Town Council. There are three constituencies; Mathioya, Kiharu and Kangema. 


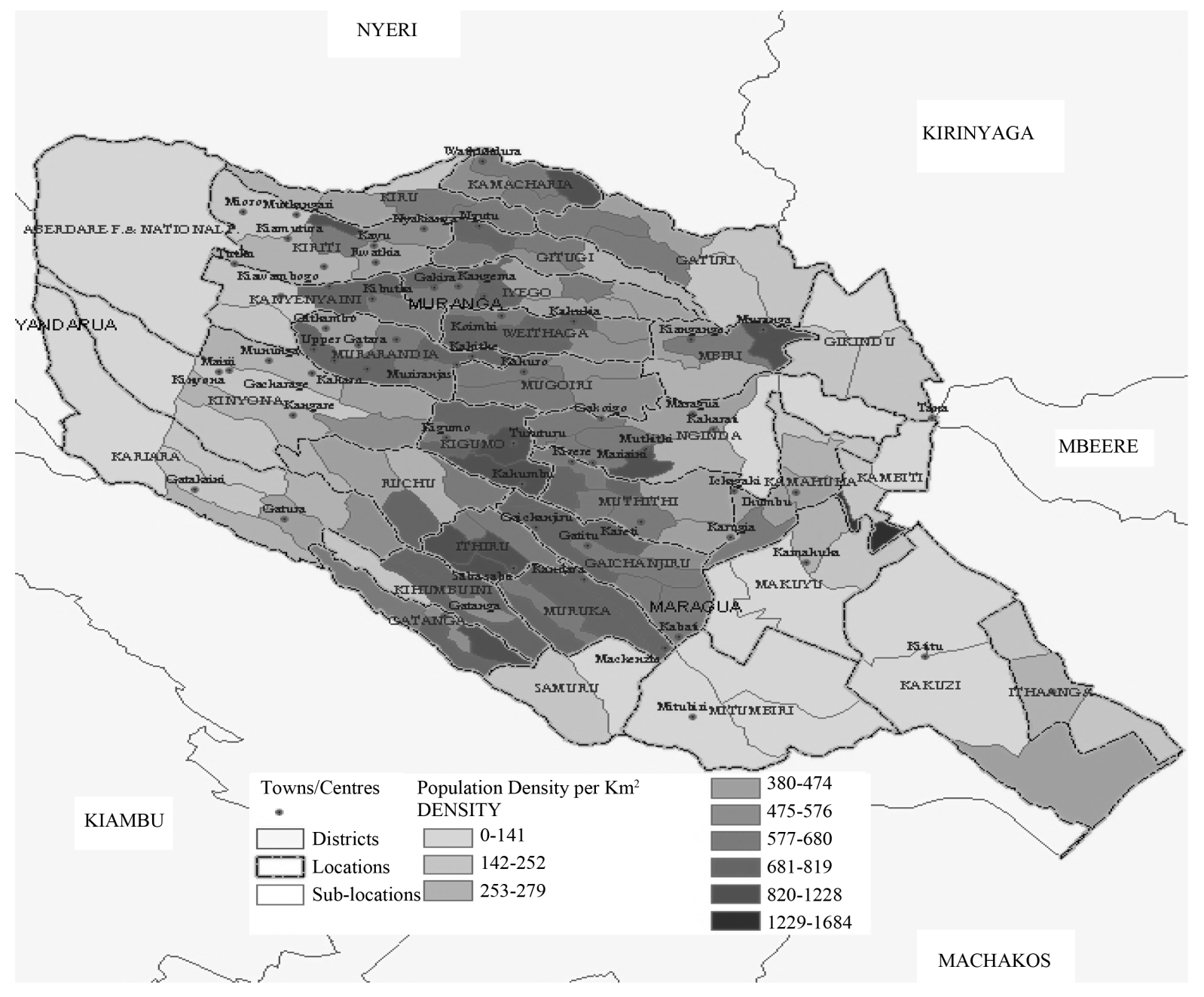

Figure 1. Map of the larger Murang'a District.

\subsection{Population Size of the Study Area}

District population in 2002 according to District Statistics Office, Murang'a North District was 350,303 people and a population density of 374 per $\mathrm{Km}^{2}$. The district population growth rate is at $0.2 \%$.

\subsection{Social, Cultural and Economic Characteristics of the Study Area}

Murang'a district is a predominantly an agricultural district and average farm holdings are generally small but vary between the highlands areas, the middle zone and the low areas.

\subsection{Health Institutions and Disease Burden in Murang'a}

Government owned health facilities in the district are one District hospital (Murang'a District Hospital), two Sub-District Hospital (Muriranja's and Kangema), one Health Center (Kirigo) and 32 Dispensaries. The doctor patient ratio in the district stands at 1:30,000. Upper Respiratory Tract Infections (URTI) is very common with over 20,000 cases seen in the district in the year 2010. Perhaps it is due to the increasing levels of atmospheric pollution caused by dust, smoke and cold in some higher areas. Diarrhoeal disease is also high both in adults and children with over 17,000 cases seen in 2010 (Murang'a District Health Records Department).

\subsection{Sampling}

Purposive sampling technique was used to select both the district and constituencies where study was carried 
out.

\subsection{SAMPE SIZE}

Since the total population of the selected area was known and the prevalence rate of the condition of interest was also known, the sample size was determined using the formula as given by Kothari (2004) for finite population [46]. The assumptions were that the sample was representative, sampling error was small, the sample was viable in the context of funds available for the research study and results from the study will be generalizable.

$$
n=\frac{Z^{2} p q N}{e^{2}(N-1)+Z^{2} p q}
$$

Given $n=$ desired sample size

$Z=1.96$ at $95 \%$ confidence interval (C.I)

$p=8 \%$. (WHO Diabetes Mellitus prevalence world wide).

$q=1-p(1-0.08)=0.92$

$e=$ level of statistical significance set $(0.05)$

$N=$ Total population in the district $(350,000)$

Therefore:

$$
n=\frac{1.96^{2} \times 0.08 \times 0.92 \times 350,000}{0.05^{2}(350,000-1)+1.96^{2} \times 0.08 \times 0.92}=\frac{98959.616}{874.998+0.283}=113.06
$$

The minimum sample size to be taken therefore, was approximately 120 Diabetic patients living in Murang'a District at the time of the study. For the purpose of this study a sample size of 258 respondents was used to ensure the sample was representative.

\subsection{Data Collection}

A structured interview schedule was used for data collection and was administered by the research assistants. The rationale for using this method was because of the possibility of some of the participants not being literate and the method also provided the researcher with an opportunity of exploring more and getting the information that may not be given through other methods like questionnaires. The interviews were conducted by the principal investigator and four research assistants. At the beginning of study the research assistants were trained on data collection and were oriented on the tool to be used for data collection. The tools were also pre-tested in Murang'a District Hospital to ensure they were understandable and were collecting the intended data. All the interviewees were assured of confidentiality and that none of their details like names would be disclosed. This was done to ensure that the participants would answer the questions without fear. Records from Murang'a District Hospital were also reviewed initially to ascertain the prevalence rates of diabetes and possible causes of frequent admissions.

\subsection{Data Analysis}

Following coding of data it was then entered into a computer using SPSS soft ware version 11.50 which was used for basic data analysis. Data cleaning was done by running frequencies and all inconsistencies and errors in data entry were corrected.

Descriptive statistics such as means, frequencies and percentages and other measures of central tenderncies analyzed using SPSS were used to describe and summarize the data. Chi squire was done independently and was used to find out the significant association between categorical data. Analysis of Variance (ANOVA) was used for comparison of age means between male and female patients to find whether there was any significant difference in age means.

\section{Results}

\subsection{Social Demographic Characteristics of the Respondents}

Among those interviewed thirty six percent (36\%) were males while 64\% were females. Gender was found to 
have no influence in the use of herbal remedies $\left(x^{2}=1.09\right.$, d. $\left.f=1, P>0.05\right)$. The ages of the participants were varied with the age of the youngest being 14 years while the oldest was over 90 years. Based on calculations the mean age for the whole group was 59 yrs. Mean age for females was 58.2 yrs while for males was 60.0 yrs.

There was no significant $(\mathrm{P}>0.05)$ difference in age means (as per ANOVA) between the male patients and female patients. The peak ages for the groups were between 61 - 70 years. Majority of those interviewed (88\%) had attained at least primary education while $12 \%$ said they had no formal education. Worth noting is that of the $88 \%$ who declared having had some level of education $53 \%$ of them went up to primary level only. Table 1 summarizes the socio-demographic characteristics of the respondents.

On analysis (Table 2) level of education was found to have a significant influence on use or non-use of herbal remedies $\left(\mathrm{x}^{2}=156.49\right.$, d.f $\left.=3, \mathrm{P}<0.05\right)$ with those higher in education using more, while gender as indicated earlier) was found to have no influence in the use of herbal remedies $\left(x^{2}=1.09\right.$, d. $\left.f=1, P>0.05\right)$.

\subsection{Occupation}

The main source of household income was farming accounting for (60.5\%) of the household income. Those who were employed were $13 \%$ while those in business were $11 \%$. Figure 2 gives a summary of the source of income of the respondents.

Table 1. Socio-demographic characteristics of the study respondents.

\begin{tabular}{cccc}
\hline Characteristic & Description & Frequency & Percentage \\
\hline Sex $(\mathrm{n}=258)$ & Male & 92 & 36 \\
& Female & 166 & 64 \\
& $11-20$ & 8 & 3.1 \\
Age in Years $(\mathrm{n}=258)$ & $21-30$ & 10 & 3.9 \\
& $31-40$ & 16 & 6.2 \\
& $41-50$ & 44.1 & 19.8 \\
Level of Education $(\mathrm{n}=258)$ & $51-60$ & 51 & 32.2 \\
& $61-70$ & 83 & 17.8 \\
& No formal education & 46 & 12.0 \\
\hline
\end{tabular}

Table 2. Influence of socio-demographic factors on use of herbal remedies.

\begin{tabular}{|c|c|c|c|c|c|c|}
\hline \multicolumn{2}{|c|}{ Variable } & \multirow{2}{*}{$\begin{array}{l}\mathrm{N} \\
92\end{array}$} & \multirow{2}{*}{$\begin{array}{c}\text { Percentage } \\
36\end{array}$} & \multirow{2}{*}{$\begin{array}{c}\text { Use herbal } \\
\text { Remedies } \\
14\end{array}$} & \multirow{2}{*}{$\begin{array}{c}\text { Don't use herbal } \\
\text { Remedies } \\
78\end{array}$} & \multirow{2}{*}{$\begin{array}{l}\text { Significance } \\
x^{2}=1.09\end{array}$} \\
\hline \multirow{3}{*}{ Gender } & Male & & & & & \\
\hline & Female & 166 & 64 & 18 & 148 & \multirow{2}{*}{$\begin{array}{c}\mathrm{df}=1 \\
\mathrm{P}>0.05\end{array}$} \\
\hline & Totals & 258 & 100 & 32 & 226 & \\
\hline \multirow{5}{*}{ Education } & $\begin{array}{l}\text { No formal } \\
\text { education }\end{array}$ & 31 & 12.0 & 3 & 28 & \multirow{5}{*}{$\begin{array}{c}\mathrm{x}^{2}=156.49 \\
\mathrm{df}=3 \\
\mathrm{P}<0.05\end{array}$} \\
\hline & Primary & 137 & 53.1 & 12 & 125 & \\
\hline & Secondary & 56 & 21.7 & 9 & 47 & \\
\hline & Tertiary & 34 & 13.2 & 8 & 26 & \\
\hline & Totals & 258 & 100 & 32 & 226 & \\
\hline
\end{tabular}




\section{Occupation of respondents}

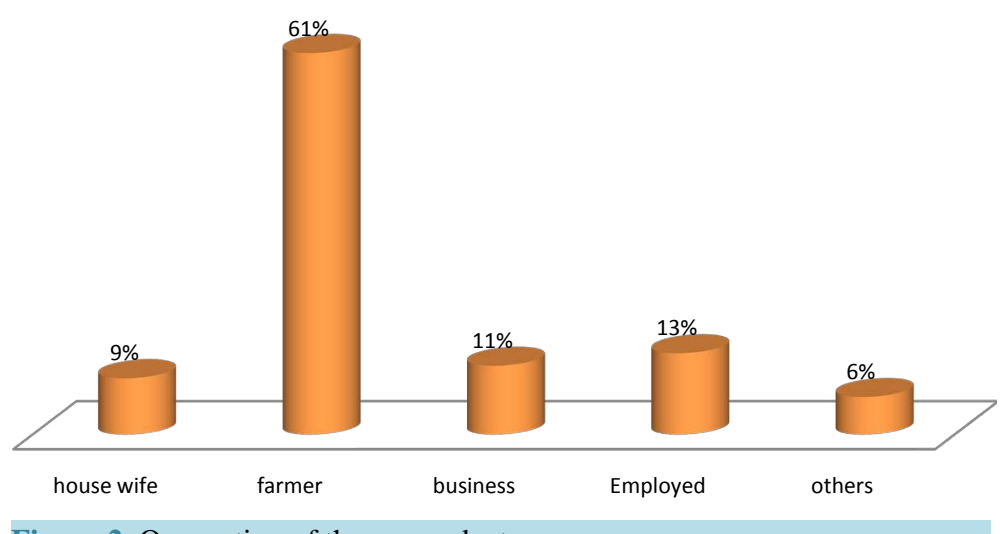

Figure 2. Occupation of the respondents.

This finding on occupation agrees with the findings on education in which majority of those interviewed had gone up to primary level. This shows that there exists a relationship between level of education and type of occupation $\left(x^{2}=51.078\right.$, d.f $=4, \mathrm{P}<0.05$ ) (Table 3 ) whereby those with low education levels opt to work in farms as their level of education may not allow them to work in offices.

\subsection{Participant Diabetes Background}

This section covers aspects concerning the patients such as when they were diagnosed with diabetes mellitus, where the diagnosis was made, whether they have ever been admitted in hospital because of the same disease, whether they have family members with diabetes and how they have been managing their condition.

\subsection{History of Diagnosis}

Majority of those interviewed were diagnosed between 2006 and 2010 (41.9\%). Only 7.8\% of those interviewed, were diagnosed in 1990 or before 1990 (Figure 3).

\subsection{Admission History}

Majority of the interviewees said they have been admitted at least once due to diabetes or its complications. 65.1\% of those interviewed admitted having ever been hospitalized at least once due to diabetes or its complications. Among those with history of admission $49 \%$ admitted having been admitted once (refer to Figure 4).

A significant number of the respondents (15\%) said that they were diagnosed with diabetes mellitus when already admitted in the wards prior to which period they had no idea that they were diabetic. This calls for aggressive screening of all people since it seems many people are moving around unaware of the fact that they may be diabetic.

\subsection{Family History of Diabetes}

In terms of diabetes running along the family line, majority of those interviewed (50.4\%) have family members suffering from diabetes while $49.6 \%$ of those interviewed said they don't have family members with diabetes mellitus (refer to Figure 5).

\subsection{Who among the Family Members Has Diabetes}

In this study we found out that of those related to the interviewed patients $22 \%$ were parents, either the mother or the father, $23 \%$ were siblings, either brothers or sisters, $4.3 \%$ were either aunts or uncles while the remaining $2 \%$ were others including cousins (refer to Figure 6). 
Table 3. Influence of education on occupation.

\begin{tabular}{|c|c|c|c|c|c|c|c|}
\hline & iable & House-wife & Farmers & Business & Employed & Others & Signi \\
\hline \multirow{4}{*}{ Education } & $\begin{array}{c}\text { Up-to Primary } \\
\text { level }\end{array}$ & 18 & 121 & 17 & 6 & 6 & $\begin{array}{c}x^{2}=51.078 \\
\text { d.f }=4\end{array}$ \\
\hline & \multirow{2}{*}{$\begin{array}{l}\text { Secondary level } \\
\text { and beyond }\end{array}$} & \multirow{2}{*}{6} & \multirow{2}{*}{35} & \multirow{2}{*}{11} & \multirow{2}{*}{28} & \multirow{2}{*}{10} & $\mathrm{P}<0.05$ \\
\hline & & & & & & & Reject null \\
\hline & Total & 24 & 156 & 28 & 34 & 16 & $\begin{array}{l}\text { significant } \\
\text { association. }\end{array}$ \\
\hline
\end{tabular}

\section{Dates when respondents were diagnosed with diabetes mellitus}

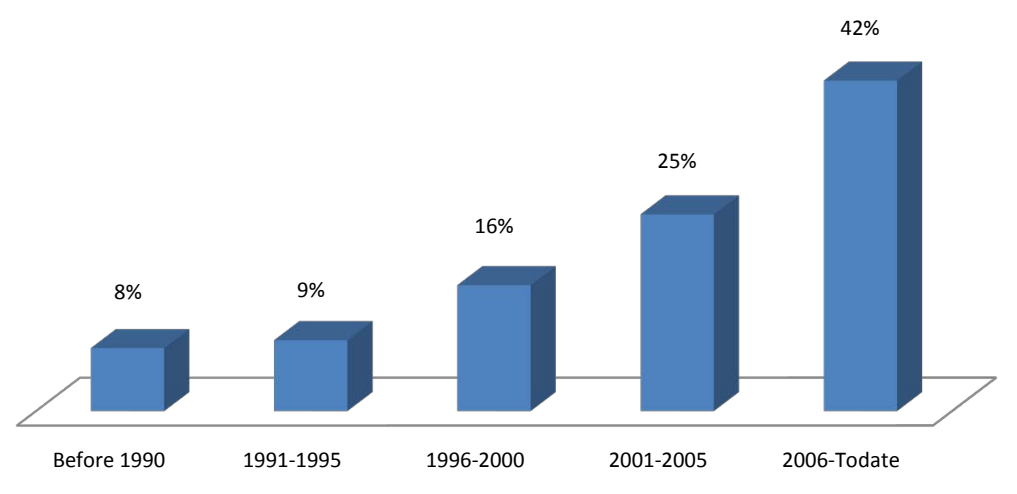

Figure 3. Dates of diagnosis.

\section{History of admission in hospital}

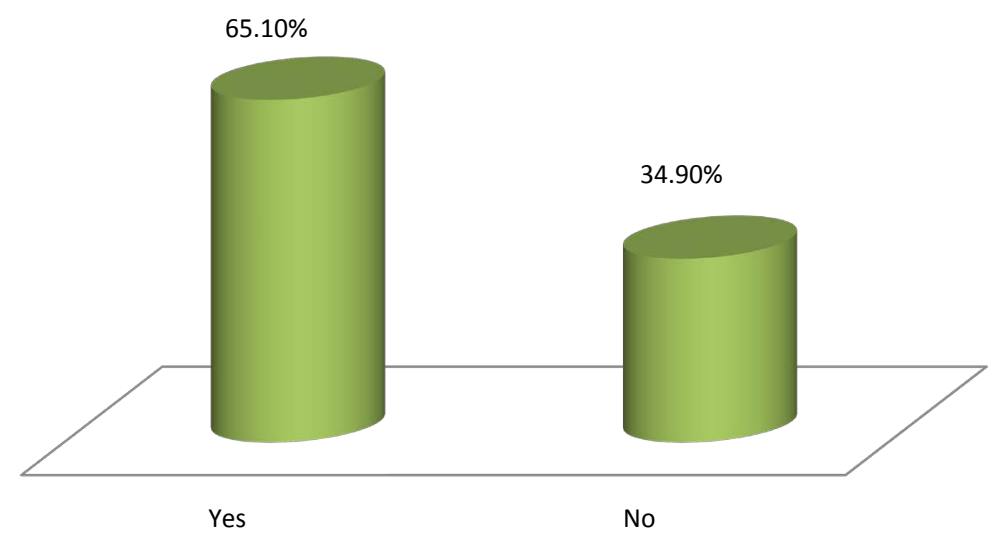

Figure 4. History of admission.

\subsection{Management of Diabetes}

In terms of diabetes management, majority of the patients (48.1\%) said that they use a combination of diet and oral hypoglycaemics in management of their condition. Those using insulin alone were $17.4 \%$, while $8.5 \%$ said they use insulin and diet in managing their condition. It is worth noting that $12.4 \%$ of those interviewed said that they use herbal remedies as part of their diabetes management regimen. Among those using herbal remedies, 3.5\% said they are very keen on their diet which in combination with herbal remedies works out very well for them (Table 4). 


\section{Family History of diabetes}

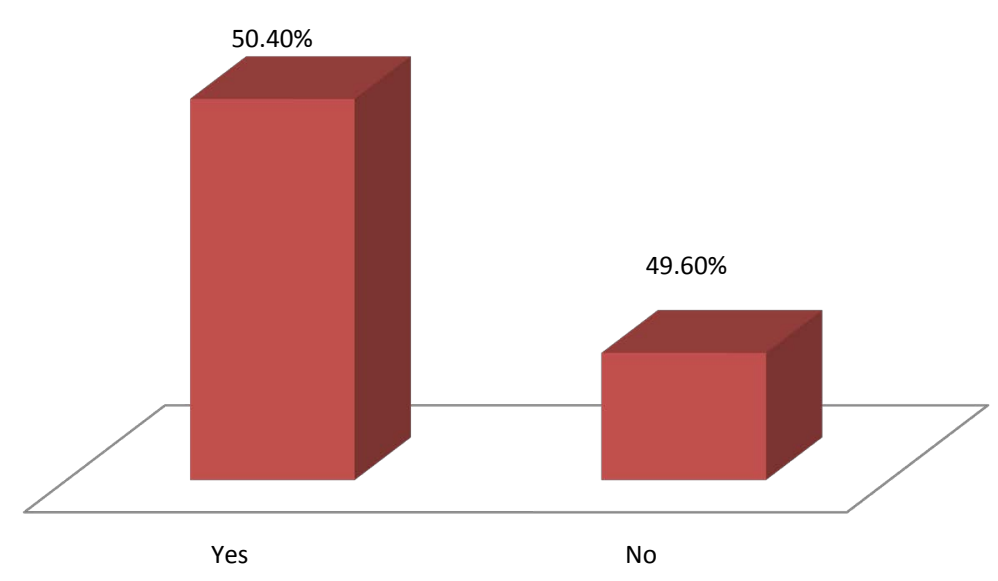

Figure 5. Family history of diabetes.

\section{Family members with diabetes}

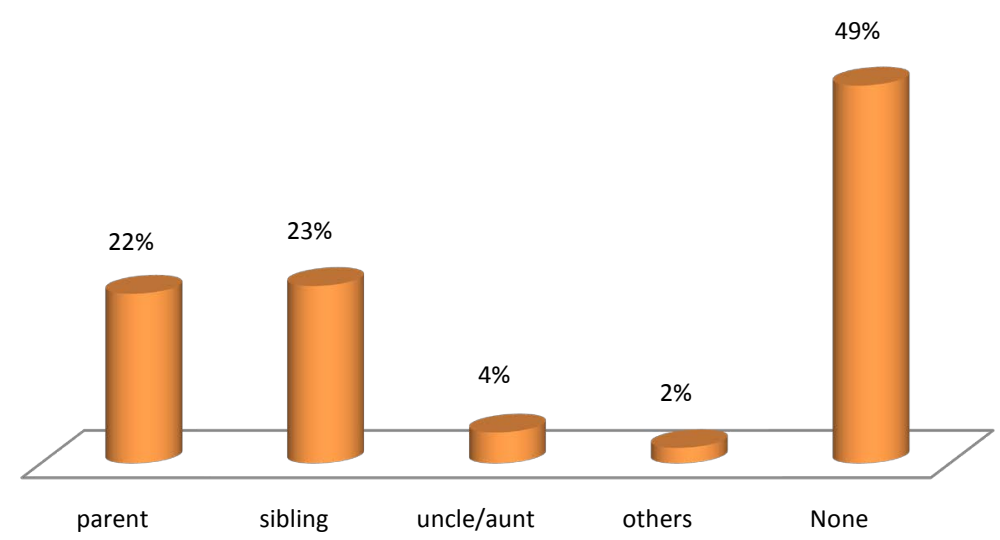

Figure 6. Family members with diabetes.

Table 4. Diabetes management among patients interviewed.

\begin{tabular}{ccc}
\hline Diabetes Management Modes among respondents & Frequency & Percentage \\
\hline Insulin & 45 & 17.4 \\
Oral hypoglycaemics & 16 & 7.2 \\
Diet & 19 & 48.1 \\
Diet and Drugs & 124 & 1.2 \\
Herbal Remedies & 3 & 2.3 \\
Oral hypoglycaemics Diet and herbal remedies & 6 & 3.5 \\
Diet and Herbal & 9 & 2.7 \\
Insulin, diet and herbal remedies & 7 & 2.7 \\
Oral hypoglycaemics and herbal remedies & 7 & 8.5 \\
\hline
\end{tabular}




\subsection{Diabetes Education and Clinic Attendance}

This section tackles issues on diabetes education, whether clinicians gave relevant information to patients or not, including information on diabetes management and control and issues to do with clinic attendance.

\subsection{Information on Diabetes}

Over $98.4 \%$ of the interviewees admitted having been given information on diabetes at the time diagnosis was made. Only $1.6 \%$ of those interviewed admitted never being given any information on diabetes on diagnosis despite the fact that they were diagnosed in the hospital (refer to Table 5).

Information given included healthy living styles like the type of diet they should take, about exercises, how to protect themselves like putting on shoes, signs and symptoms that can lead them to seek medical attention and generally on management of the disease itself.

\subsection{Advice Given on Management and Control of Diabetes}

On question of what advice was given on diabetes management and control, majority of those respondents interviewed admitted being advised on diet (46\%), others were advised on diet and drugs (41\%), for $6 \%$ a lot of emphasis was laid on use of drugs (both insulin and oral hypoglycaemics). $7 \%$ of those interviewed said they were adviced on other modes of diabetes control like exercises, putting on shoes to protect their feet among others. Only $1.6 \%$ admitted not being given any direction in as far as diabetes management and control was concerned. Worth noting was that no patient admitted ever being advised on use of herbal remedies (refer to Figure 7).

\subsection{Clinic Attendance}

Over $87 \%$ of those interviewed, said that they attend clinic regularly while $13 \%$ clearly indicated that they were not attending clinics regularly due to varied reasons (refer to Figure 8). It is worth noting that there was found to exist no relationship between clinic attendance and use of herbal remedies $\left(x^{2}=0.259\right.$, d.f $\left.=1, P>0.05\right)$.

On analysis as indicated earlier, clinic attendance was not found to have any significant relationship with use of herbal remedies while perceptions were found to influence use of herbal remedies ( refer to Table 6).

\subsection{Reasons for Not Attending Clinic Regularly}

Reasons given for not attending clinic regularly were varied. Financial problems were sited as they main reason for not attending clinic regularly whereby $47 \%$ of the respondents said they simply could not afford, given the distance from their homes to the facility whereby they have to use fare, and also the hospital charges. Twenty-six

Table 5. Information on Diabetes.

\begin{tabular}{cc}
\multicolumn{1}{c}{ Information on diabetes } \\
\hline Information on diabetes given on diagnosis & $98.4 \%$ \\
Information on diabetes not given on diagnosis & $1.6 \%$ \\
\hline
\end{tabular}

Table 6. Influence on Information on diabetes, Clinic attendance and Perceptions on use of herbal remedies.

\begin{tabular}{|c|c|c|c|c|c|}
\hline \multicolumn{2}{|c|}{ Variable } & $\mathrm{N}$ & Use herbal Remedies & Don't use herbal Remedies & Significance \\
\hline \multirow{3}{*}{ Clinic Attendance } & Attends Regularly & 225 & 27 & 198 & \multirow{3}{*}{$\begin{array}{c}x^{2}=0.259 \\
\text { d.f }=1 \\
P>0.05\end{array}$} \\
\hline & $\begin{array}{l}\text { Does Not Attend } \\
\text { regularly }\end{array}$ & 33 & 5 & 28 & \\
\hline & Total & 258 & 32 & 226 & \\
\hline \multirow{3}{*}{$\begin{array}{l}\text { Perceptions on Herbal } \\
\text { Remedies }\end{array}$} & Positive Perceptions & 83 & 28 & 55 & \multirow{3}{*}{$\begin{array}{c}x^{2}=51.31 \\
d . f=1 \\
P<0.05\end{array}$} \\
\hline & Negative Perceptions & 175 & 4 & 171 & \\
\hline & Total & 258 & 32 & 226 & \\
\hline
\end{tabular}




\section{Advice given to those interviewed}

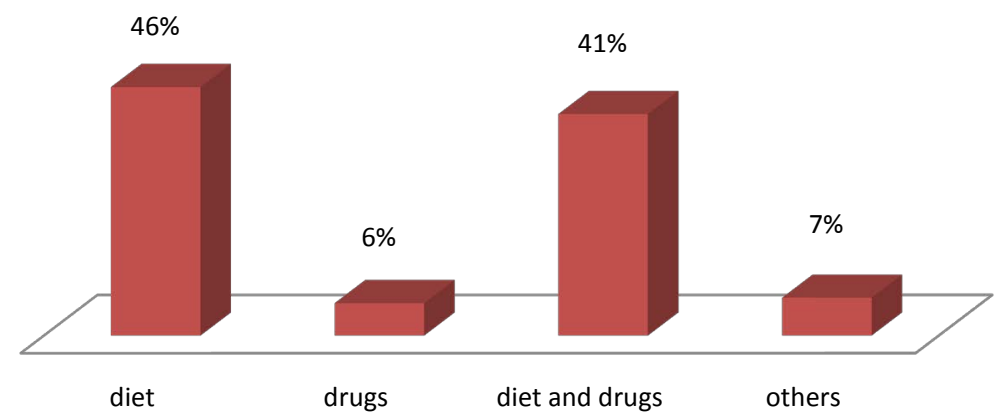

Figure 7. Advice given to those on modes of diabetes management on diagnoses.

\section{Attends Clinic in Hospital Regularly}

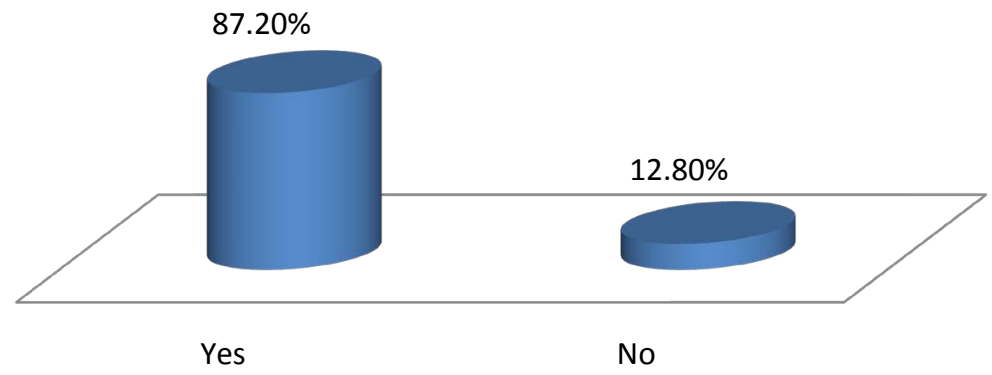

Figure 8. Clinic attendance.

percent (26\%) said that they had just been diagnosed and as such they had not started attending clinics. Six percent (6\%) admitted that their condition was not complicated and they could not see the reason of spending time and resources to go to the hospital. A small percentage (3\%) said that they had faith that God is able to intervene and heal them miraculously (refer to Figure 9).

\subsection{Extra Advice Given on Subsequent Visits}

Asked whether they have been given extra advice on management of diabetes on subsequent clinic attendance, 88.4\% admitted having been given extra advice on management and control of diabetes while $11.6 \%$ said that no further advice have been given to them apart from what they were told on diagnosis (refer to Table 7).

\subsection{Findings on Perceptions and Use of Herbal Remedies.}

This section gives an outline of the findings on perceptions on herbal remedies, use of the same among the respondents, the reasons that were given for either using or not using the herbal remedies, herbal remedies commonly used and findings on whether the respondents were combining herbal remedies with current modern drugs.

\subsection{Perceptions on Herbal Remedies}

Perceptions on herbal remedies were varied among the people interviewed. As Table 8 of those interviewed 20\% said they don't believe that herbal remedies work while $16 \%$ said as far as they were concerned herbal remedies are not good. Ten percent (10\%) said they had never thought seriously about herbal remedies while another 11\% said they simply don't trust the herbal remedies. Twenty seven percent (27\%) said they had no problem with herbal remedies and given a chance would go ahead and use them. Some respondents (9\%) said the only reason 


\section{Reasons for not attending clinic regularly}

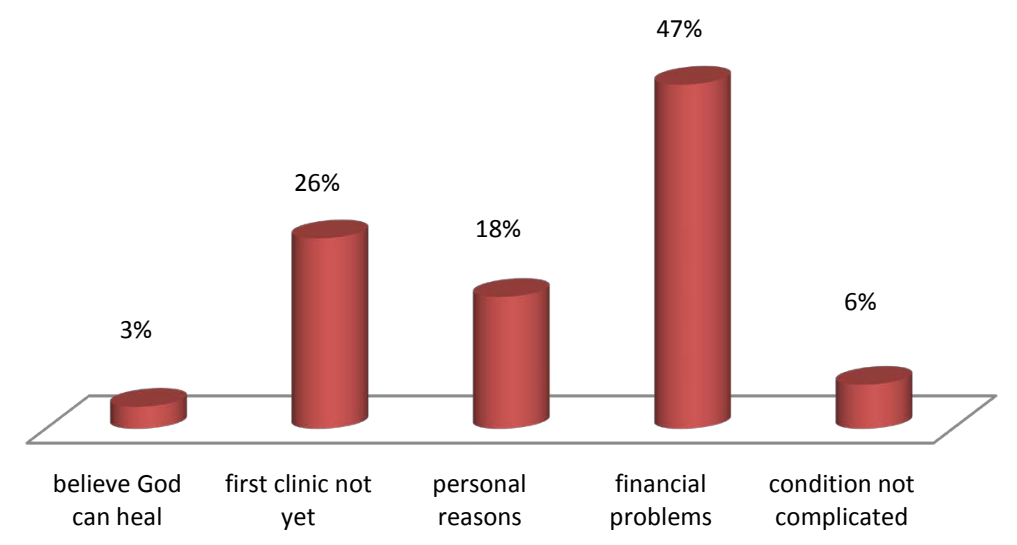

Figure 9. Reasons for not attending clinic regularly.

Table 7. Extra advice given on subsequent visits.

\begin{tabular}{ccc}
\hline & Extra Advice Given During Subsequent Visits \\
\hline Yes & $88.4 \%$ \\
No & $11.6 \%$ \\
\hline
\end{tabular}

why they are not using herbal remedies is because they fear combining herbal remedies with conventional medicine, otherwise they would use herbal remedies.

Those who said that herbal remedies works, said that the times they have used them whatever the signs and symptoms they had, had disappeared and some of them went as far as admitting that if used well herbal remedies can be more efficacious than contemporary medicines.

\subsection{Awareness of Existence of Herbal Clinics and Visiting of the Same}

Asked about awareness of any herbal institution in their locality, $86.8 \%$ of those interviewed admitted they were aware, only $13 \%$ said they were not aware. $14.3 \%$ admitted ever visiting the same, while $85.7 \%$ said they had never visited herbal clinics (refer to Table 9).

\subsection{Use of Herbal Remedies among Diabetics}

On the question of use of herbal remedies $12.4 \%$ of those interviewed in admitted ever having used herbal remedies to manage either blood sugar levels or other conditions resulting from diabetes while $87.6 \%$ admitted having never used herbal remedies for diabetes management (refer to Figure 10).

\subsection{Reasons for Using Herbal Remedies}

Among the respondents that admitted having used herbal remedies for diabetes or related conditions management, $45 \%$ said they were trying to see whether herbal remedies work while another $26 \%$ of the same group said they believed herbal remedies works in them, $6 \%$ said they used following advice either from their own children or herbal suppliers and 3\% said their use was as a result of adverts either from radio or television (refer to Figure 11).

Worth noting from the above results, is the varied reasons given for using herbal remedies.

\subsection{Reasons for Not Using Herbal Remedies}

The main reasons given by those interviewed for not using herbal remedies was their lack of faith in effectiveness of herbal remedies in treating diabetes and not being sure of what is contained within herbal remedies as a result of which they don't trust them (29\%). Another big group of respondents $27 \%$ said the reason why they 


\section{Use of herbal remedies among diabetics}

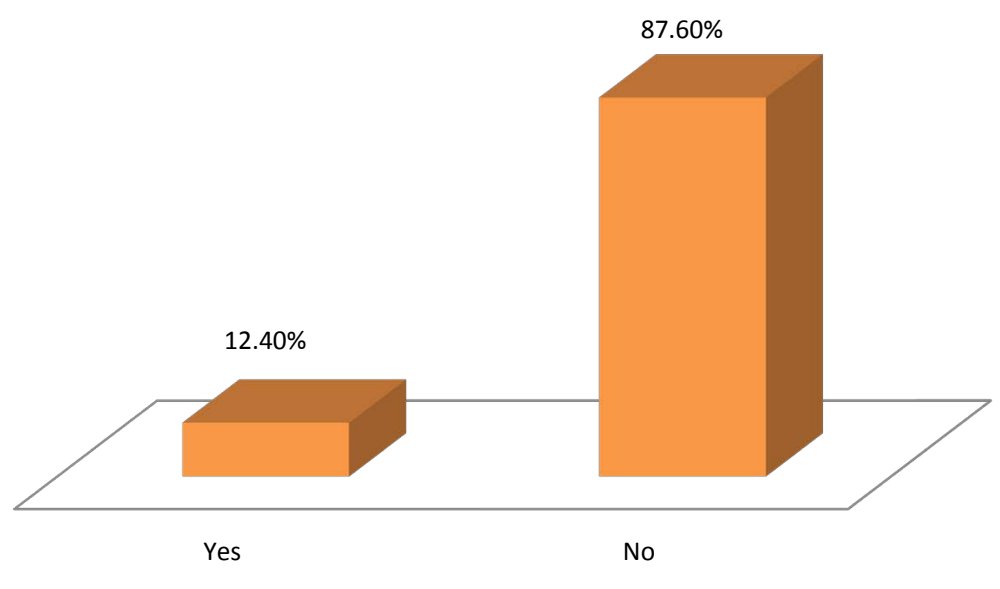

Figure 10. Use of herbal remedies among diabetics.

\section{Reasons for using herbal remedies}

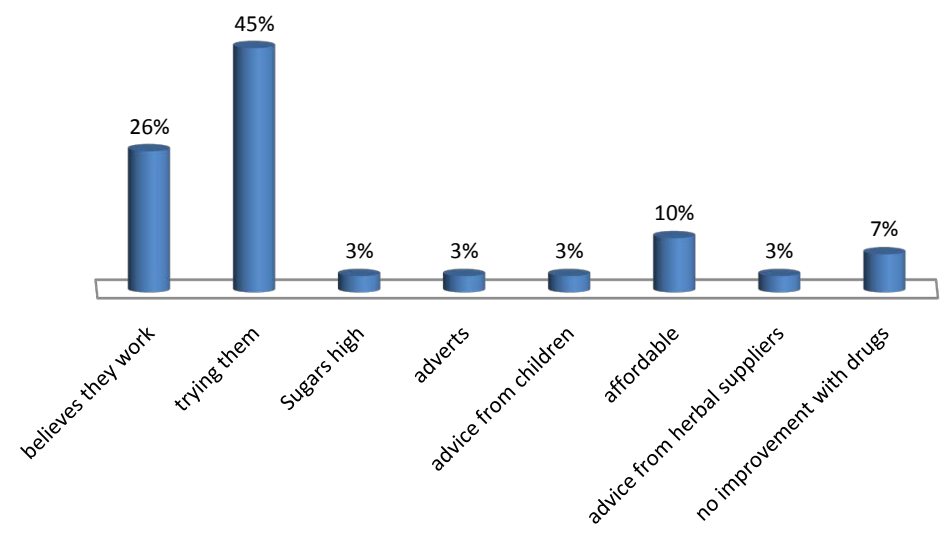

Figure 11. Reasons for using herbal remedies.

Table 8. Respondents perceptions on herbal remedies.

\begin{tabular}{ccc}
\hline Perceptions $(\mathrm{n}=258)$ & Frequency & Percentage \\
\hline Works & 42 & 16 \\
Does not work & 51 & 20 \\
Never thought about it & 26 & 10 \\
No good & 42 & 9 \\
Cant use together with drugs & 22 & 3 \\
Brings more complications & 7 & 11 \\
Don't trust them & 27 & 6 \\
Don't know much about them & 15 & 5 \\
Are traditional & 12 & 1 \\
Cause no harm & 2 & 4 \\
Good but expensive & 9 & 1 \\
Effective but slow & 3 & 9 \\
\hline
\end{tabular}


don't use herbal remedies is simply because they are on modern drugs and they would not wish to mix with herbal remedies. $20 \%$ said that from experience they don't believe that herbal remedies work, while $11 \%$ said that they don't use herbal remedies because of fear of side effects associated with them. Two percent (2\%) of those interviewed stated the reason for not using as not having met a credible herbal remedies provider otherwise if they get one they could trust they would start using (refer to Table 10).

\subsection{Herbal Remedies Used}

Either by design of the people providing herbal remedies or due to ignorance of the patients, more than $90 \%$ of the patients using herbal remedies didn't know the names and the composition or the contents in the herbal remedies they were using and the few who seemed to have some ideas were guessing what could be contained in these herbal remedies. As a result they were calling them mainly by the name of the provider e.g. Kamirithu herbs, alpha herbs etc. $4.7 \%$ of those interviewed either could not remember or did not actually know the name of the herbs they had used (refer to Figure 12).

\subsection{Combining Herbal Remedies with Current Modern Medicine}

Asked whether they have been combining herbal remedies with modern medicine, majority of those using herbal remedies admitted doing it. Of those using herbal remedies, 7\% admitted that they were combining herbal remedies with modern drugs while 5.4\% admitted using herbal remedies alone (refer to Figure 13).

This finding of combining of herbal remedies is surprising and the patients need to be alerted on potential dangers of the same.

\section{Conclusions and Recommendations}

\subsection{Conclusions}

From the study findings, the following conclusions were drawn:

Table 9. Awareness of existence of herbal clinic.

\begin{tabular}{ccc}
\hline & Awareness of existence of herbal clinic nearby \\
\hline Yes & $86.8 \%$ \\
No & Ever visited Herbal clinic & $13.2 \%$ \\
\hline Yes & $14.3 \%$ \\
No & $85.7 \%$ \\
\hline
\end{tabular}

Table 10. Reasons for not using herbal remedies.

\begin{tabular}{ccc}
\hline Reasons for not using herbal remedies & Frequency & Percentage \\
\hline Believes they don't work & 46 & $20 \%$ \\
Expensive & 9 & 65 \\
Do not trust them & $29 \%$ \\
Because of side effects & 24 & $11 \%$ \\
Wishes not to mix & 62 & $27 \%$ \\
Never found good provider & 5 & $2 \%$ \\
Newly diagnosed & 9 & $3 \%$ \\
Herbs are just business & $3 \%$ \\
Has seen mismanaged patients & 2 & $1 \%$ \\
No proper dosage & $1 \%$ & $1 \%$ \\
\hline
\end{tabular}




\section{Types of herbal remedies used}

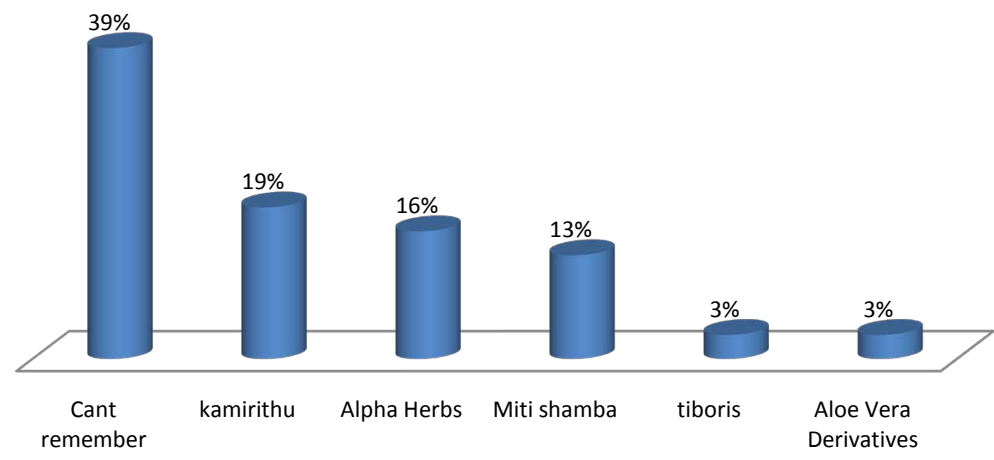

Figure 12. Types of herbal remedies used.

\section{Respondents combining herbal with conventional drugs}

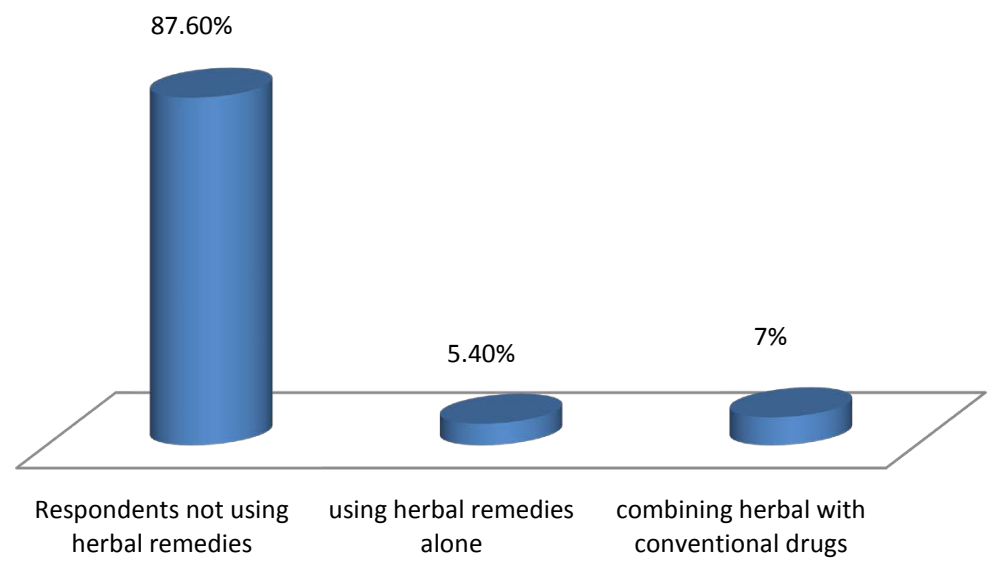

Figure 13. The group combining herbal remedies with conventional drugs.

A number of diabetic patients (15\%) were diagnosed with diabetes mellitus when already admitted in the wards prior to which period they had no idea that they were diabetic.

> Information on diabetes including its management was given to majority of patients (98\%) on diagnosis and over $86 \%$ were attending hospital clinics regularly for follow-up and therefore, this means that the reason for seeking alternative modes of treatment was not due to lack of information on diabetes but due to other reasons.

Use of herbal remedies is common (12\% of those interviewed) among diabetics in Murang’a, Kenya.

> Majority of the diabetic patients using herbal remedies (45\%) use them on trial basis not on the grounds of prior knowledge or experience.

$>$ It was also evident that combining herbal remedies with contemporary medicines ( $7 \%$ of those using herbal remedies) is a common practice among diabetics in Murang'a, Kenya despite the fact that there may be complications from interactions following using both concurrently.

\subsection{Recommendations}

The government of Kenya through the Ministry of health should encourage rigorous screening of clients and population in general for diabetes to ensure diabetes is diagnosed early and put under appropriate management.

$>$ The government of Kenya through Ministry of Health should put up a campaign educating diabetic patients 
on the potential dangers associated with combining herbal remedies with contemporary medicines due to their interactions.

\section{References}

[1] World Health Organization (2003) The World Health Report 2002-Reducing Risks, Promoting Healthy Life. WHO, Geneva.

[2] International Diabetes Federation (2003) Diabetes Atlas. 2nd Edition, IDF, Brussels.

[3] Wild, S., et al. (2004) Global Prevalence of Diabetes: Estimates for 2000 and Projections for 2030. Diabetes Care, 27, 1047-1053. http://dx.doi.org/10.2337/diacare.27.5.1047

[4] Atkinson, M.A. and Eisenbarth, G. (2001) Type 1 Diabetes: New Perspective on Disease Pathogenesis and Treatment. The Lancet, 358, 221-229. http://dx.doi.org/10.1016/S0140-6736(01)05415-0

[5] International Diabetes Federation (2006) Diabetes Atlas. 3rd Edition, IDF, Brussels.

[6] Mario, A. and Alla, S. (2008) Diabetes in Sub-Saharan Africa: Kenya, Mali, Mozambique, Nigeria, South Africa and Zambia. International Journal of Diabetes in Developing Countries, 28, 101-108. http://dx.doi.org/10.4103/0973-3930.45268

[7] Chege, M. (2007) Risk Factors for Type 2 Diabetes Mellitus among Patients Attending a Rural Kenyan Hospital. African Journal of Primary Health Care and Family Medicine, 2, No. 1. http://dx.doi.org/10.4102/phcfm.v2i1.96

[8] Souhami, L. and Moxham, J. (1994) Textbook of Medicine. Churchill Livingstone, London.

[9] Palinkas, L. and Kabongo, M. (2000) The Use of Complementary and Alternative Medicine by Primary Care Patients. Department of Family and Preventive Medicine, University of California, San Diego, La Jolla 92093-0807, USA. Journal of Family Practice, 49, 1121-1130.

[10] World Health Organization (1999) Definition, Diagnosis and Classification of Diabetes Mellitus and Its Complication. Department of Non-Communicable Disease Surveillance, Geneva.

[11] Rother, K.I. (2007) Diabetes Treatment-Bridging the Divide. The New England Journal of Medicine, 356, $1499-1501$. http://dx.doi.org/10.1056/NEJMp078030

[12] Tierney, L., McPhee, S. and Papadakis, M. (2002) Current Medical Diagnosis \& Treatment. International Edition, Lange Medical Books/McGraw-Hill, New York, 1203-1215.

[13] Leslie, R.G. and Robins, D.C. (1995) Diabetes: Clinical Science in Practice. Cambridge University Press, Cambridge.

[14] Masters, S.L., Dunne, A., Subramanian, S.L., et al. (2010) Activation of the NLRP3 Inflammasome by Islet Amyloid Polypeptide Provides a Mechanism for Enhanced IL-1 $\beta$ in Type 2 Diabetes. Nature Immunology, 11, 897-904

[15] Pickup, J. and Williams, G. (1997) Textbook of Diabetes. 2nd Edition, Blackwell Scientific, Oxford.

[16] Lawrence, J.M., Contreras, R., et al. (2008) Trends in the Prevalence of Preexisting Diabetes and Gestational Diabetes Mellitus among a Racially/Ethnically Diverse Population of Pregnant Women, 1999-2005. Diabetes Care, 31, 899-904. http://dx.doi.org/10.2337/dc07-2345

[17] Byrne, M., Sturis. J., et al. (1996) Altered Insulin Secretory Response to Glucose in Diabetic and Nondiabetic Subjects with Mutations in the Diabetes Susceptibility Gene MODY 3 on Chromosome 12. Diabetes, 45, 1503-1510. http://dx.doi.org/10.2337/diab.45.11.1503

[18] Pandit, M.K., Burke, J., et al. (1993) Drug-Induced Disorders of Glucose Tolerance. Annals of Internal Medicine, 118, 529-540. http://dx.doi.org/10.7326/0003-4819-118-7-199304010-00008

[19] Frier, B.M. and Fisher, B.M. (1999) Hypoglycaemia in Clinical Diabetes. John Wiley, Chichester.

[20] Williams, G. and Monson, J. (1994) Diabetes Mellitus and Disorders of Lipid and Intermedially Metabolism: Textbook of Medicine. Churchill Livingstone, Edinburg.

[21] Kordella, T. (2003) New Combo Pills. Diabetes Forecast, 42.

[22] American Diabetes Association (2003) Standards of Medical Care for Patients with Diabetes Mellitus. Diabetes Care, 26, S33-S50.

[23] Huffman, M. (2003) Animal Self-Medication and Ethno-Medicine: Exploration and Exploitation of the Medicinal Properties of Plants. Proceedings of the Nutrition Society, 62, 371-381. http://dx.doi.org/10.1079/PNS2003257

[24] Crutchfield, D.B. (2003) Oral Antidiabetic Agents: Back to the Basics. Geriatric Times, 20.

[25] Diabetes Voice (2006) A Diabetes Strategy for Africa: Investing in Health, Protecting Our People. Diabetes Voice, 51.

[26] Elamin, A., Omer, M.I., Zein, K. and Tuvemo, T. (1992) Epidemiology of Childhood Type I Diabetes in Sudan, 19871990. Diabetes Care, 15, 1556-1559. http://dx.doi.org/10.2337/diacare.15.11.1556 
[27] Afoke, A., Ejeh, N., et al. (1992) Prevalence and Clinical Picture of IDDM in Nigerian Ibo School Children. Diabetes Care, 15, 1310-1312. http://dx.doi.org/10.2337/diacare.15.10.1310

[28] Swai, A.B.M., Lutale, J. and McLarty, D.G. (1993) Diabetes in Tropical Africa. Prospective Study of Incidence of Juvenile Diabetes Mellitus over 10 Years in Dares Salaam, Tanzania. British Medical Journal, 306, 1570-1572. http://dx.doi.org/10.1136/bmj.306.6892.1570

[29] Sobngwi, E., Mbanya, J., et al. (2002) Physical Activity and Its Relationship with Obesity, Hypertension and Diabetes in Urban and Rural Cameroon. International Journal of Obesity and Related Metabolic Disorders, 26, 1009-1016.

[30] Mosley, W.H., Bobadilla, J.L. and Jamison, D.T. (1993) The Health Transition: Implications for Health Policy in Developing Countries. In: Disease Control Priorities in Developing Countries, Oxford University Press, New York, 673699.

[31] Levitt, N.S., Steyn, K., et al. (1999) Modifiable Risk Factors for Type 2 Diabetes Mellitus in a Peri-Urban Community in South Africa. Diabetic Medicine, 16, 946-950. http://dx.doi.org/10.1046/j.1464-5491.1999.00185.x

[32] McLarty, D.G., Yusafai, A. and Swai, A. (1989) Seasonal Incidence of Diabetes Mellitus in Tropical Africa. Diabetic Medicine, 6, 762-765. http://dx.doi.org/10.1111/j.1464-5491.1989.tb01275.x

[33] Swai, A.B., McLarty, D.G., et al. (1990) Diabetes and Impaired Glucose Tolerance in an Asian Community in Tanzania. Diabetes Research and Clinical Practice, 8, 227-234. http://dx.doi.org/10.1016/0168-8227(90)90121-9

[34] Cooper, R.S., Rotimi, C.N., et al. (1997) Prevalence of NIDDM among Populations of the African Diaspora. Diabetes Care, 20, 343-348. http://dx.doi.org/10.2337/diacare.20.3.343

[35] Mbanya, J.C., Ngogang, J., et al. (1997) Prevalence of NIDDM and Impaired Glucose Tolerance in a Rural and an Urban Population in Cameroon. Diabetologia, 40, 824-829. http://dx.doi.org/10.1007/s001250050755

[36] Aspray, T.J., Mugusi, F., et al. (2000) Rural and Urban Differences in Diabetes Prevalence in Tanzania: The Role of Obesity, Physical Inactivity and Urban Living. Transactions of the Royal Society of Tropical Medicine and Hygiene, 94, 637-644. http://dx.doi.org/10.1016/S0035-9203(00)90216-5

[37] Ramachandran, A., Snehallata, C., et al. (1999) Impacts of Urbanization on the Lifestyle and on the Prevalence of Diabetes in Native Asian Population. Diabetes Resident Clinical Practice, 44, 207-213. http://dx.doi.org/10.1016/S0168-8227(99)00024-8

[38] Amoah, A.G., Owusu, S.K. and Adjei, S. (2002) Diabetes in Ghana: A Community Based Prevalence Study in Greater Accra. Diabetes Research and Clinical Practice, 56, 197-205. http://dx.doi.org/10.1016/S0168-8227(01)00374-6

[39] Kebaso, J.N. (2003) Prevalence Major Complications of Diabetes Mellitus and Compliance in Diabetic Patients Seeking Treatment at Kenyatta National Hospital. Masters of Public Health Thesis, Kenyatta University, Nairobi.

[40] Otieno, C.F. (2005) Diabetes Care in Kenya, Where We Are and Which Way Forward. East African Medical Journal, 82, S161-S162.

[41] Brater, D.C. and Daly, W.J. (2000) Clinical Pharmacology in the Middle Ages: Principles That Presage the 21st Century. Clinical Pharmacology \& Therapeutics, 67, 447-450. http://dx.doi.org/10.1067/mcp.2000.106465

[42] Goldman, P. (2001) Herbal Medicines Today and the Roots of Modern Pharmacology. Annals of Internal Medicine, 135, 594-600. http://dx.doi.org/10.7326/0003-4819-135-8_Part_1-200110160-00010

[43] Barnes, J. (2002) Herbal Therapeutics: An Introduction to Herbal Medicinal Products. Pharmaceutical Journal, 268, 803.

[44] Johnson, L., Strich, H., et al. (2006) Use of Herbal Remedies by Diabetic Hispanic Women in the Southwestern United States. Phytotherapy Research, 20, 250-255. http://dx.doi.org/10.1002/ptr.1820

[45] Ayyanar, M., Sankarasivaraman, K. and Ignacimuthu, S. (2008) Traditional Herbal.

[46] Kothari, C.R. (2004) Research Methodology: Methods and Techniques. 2nd Edition, New Age International Publishers, New Delhi. 
Scientific Research Publishing (SCIRP) is one of the largest Open Access journal publishers. It is currently publishing more than 200 open access, online, peer-reviewed journals covering a wide range of academic disciplines. SCIRP serves the worldwide academic communities and contributes to the progress and application of science with its publication.

Other selected journals from SCIRP are listed as below. Submit your manuscript to us via either submit@scirp.org or Online Submission Portal.
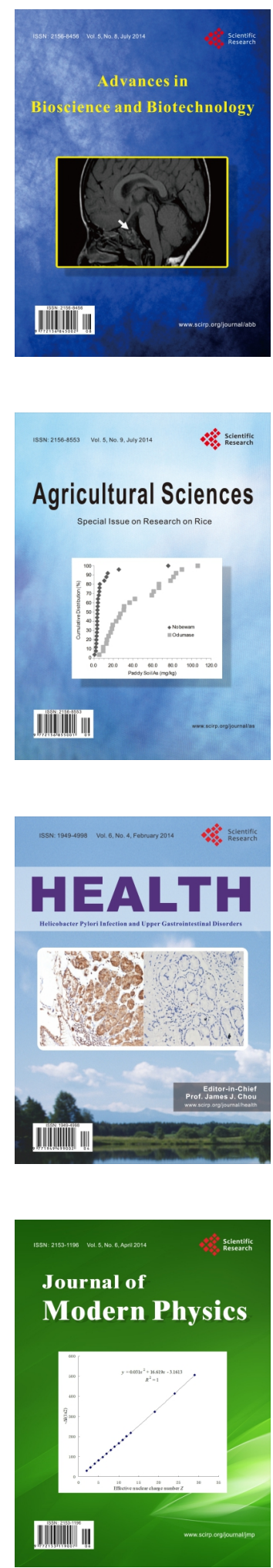
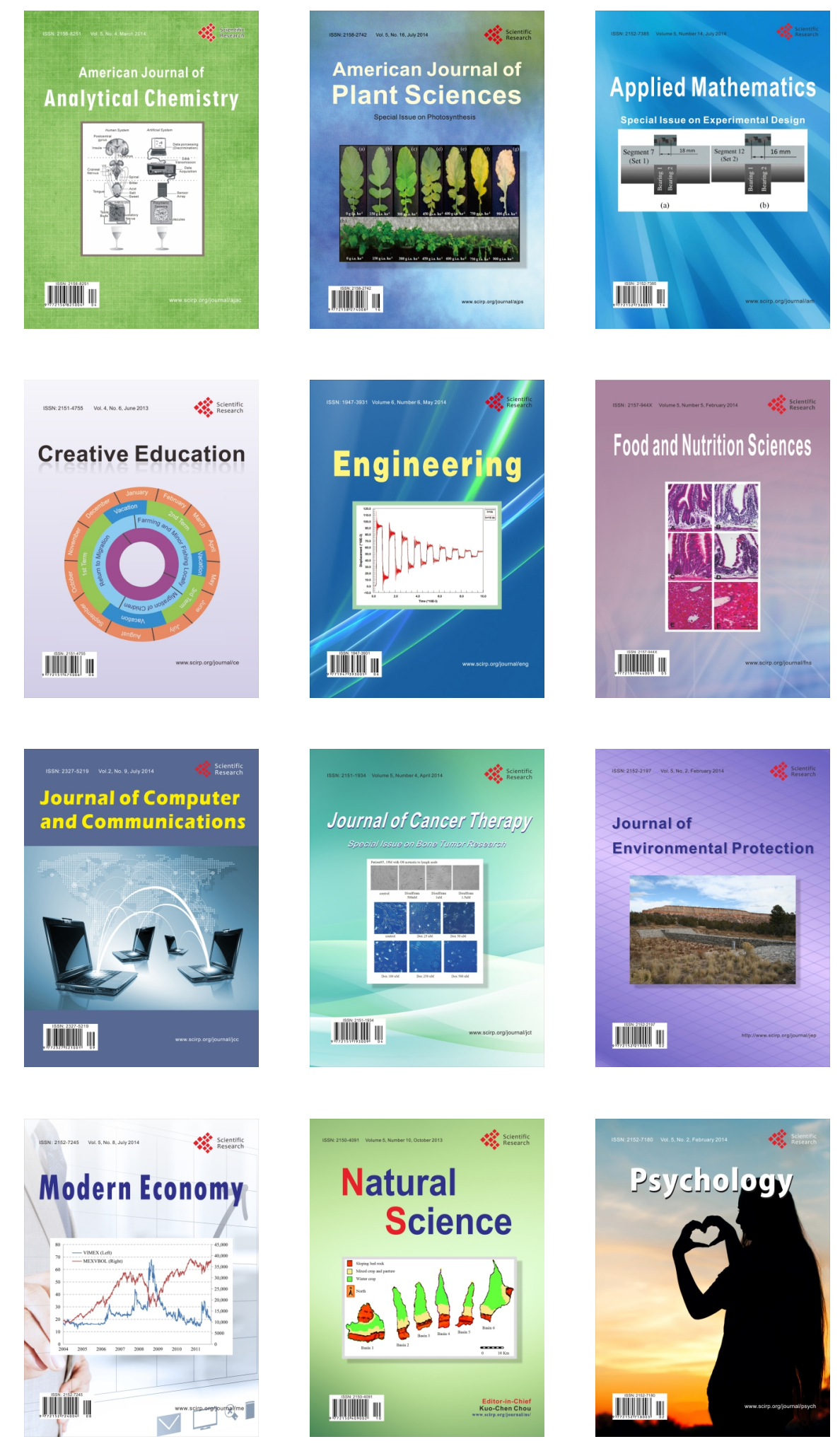